\title{
O lazer e a saúde mental das pessoas hipertensas: convergência na educação para a saúde*
}

\author{
LEISURE AND MENTAL HEALTH IN PEOPLE WITH HYPERTENSION: \\ CONVERGENCE IN HEALTH EDUCATION
}

\section{LA RECREACIÓN Y LA SALUD MENTAL EN PERSONAS HIPERTENSAS: CONVERGENCIA EN LA EDUCACIÓN PARA LA SALUD}

\author{
Vanessa Denardi Antoniassi Baldissera1, Sonia Maria Villela Bueno²
}

\section{RESUMO}

Em hipertensos, as questões relativas à manutenção da saúde mental estão sempre presentes em virtude dos determinantes psicossociais desta doença, para os quais o lazer representa importante estratégia de controle. Este trabalho objetivou realizar, por meio de uma pesquisa-ação, a Educação para a Saúde junto a um grupo de hipertensos baseada na pedagogia crítico-social, partindo da percepção dos participantes quanto ao lazer, desenvolvendo atividades educativas e, posteriormente, avaliando a opinião dos envolvidos quanto ao impacto para a vida e para a saúde mental. O lazer foi percebido pelo grupo como estratégia de enfrentamento da solidão; como construção tardia de independência; como socialização e como promoção de saúde mental. Estas percepções levaram à identificação de dois temas geradores: envelhecimento, lazer e doença crônica; conhecimento e vivências do lazer, para os quais ações educativas foram programadas, tais como dinâmicas e grupos de discussão, a fim de favorecer condições que permitiram a socialização e a troca de experiências.

\section{DESCRITORES}

Idoso

Hipertensão

Atividades de lazer

Saúde mental

Educação em saúde

\begin{abstract}
People with hypertension constantly deal with issues related to mental health due to the psychosocial determinants of this illness, and leisure is an important control strategy. The objective of this study was to promote health education to a group of hypertensive patients, through research-action, based on critical-social pedagogy, and taking into consideration the participants' perception of leisure. Educational activities were conducted and, following, an evaluation was performed regarding the subjects' opinion about the impact of leisure on their lives and mental health. The group perceived leisure as a coping strategy for loneliness and also as a late development of independence; it was also regarded as a means of socialization and as a promotion of mental health. These perceptions revealed two themes: aging, leisure, and chronic disease; and knowledge and leisure experiences. Educational actions, such as group dynamics and discussions, were planned considering these themes with the purpose of providing the necessary conditions for socializing and exchanging experiences.
\end{abstract}

\section{DESCRIPTORS \\ Aged \\ Hypertension \\ Leisure activities \\ Mental health \\ Health education}

\section{RESUMEN}

En hipertensos, los asuntos relativos a la preservación de la salud mental están siempre presentes, en virtud de los determinantes psicosociales de la enfermedad, para los que la recreación resulta una importante estrategia de control. Se objetivó realizar, mediante investigación-acción, la Educación para la Salud con grupo de hipertensos, basada en pedagogía críticosocial, partiendo de la percepción de los participantes acerca de la recreación, desarrollando actividades educativas y evaluando la opinión de los involucrados respecto del impacto en su vida y salud mental. La recreación fue percibida por el grupo como estrategia de enfrentamiento de la soledad; como construcción tardía de interdependencia; como socialización y como promoción de la salud mental. Estas percepciones permitieron identificar dos temas generadores: Envejecimiento, recreación y enfermedad crónica; Conocimiento y experiencias recreativas, para los que se programaron acciones educativas, dinámicas y grupos de discusión, ofreciendo condiciones que permitan la socialización y el intercambio de experiencias.

\section{DESCRIPTORES}

Anciano

Hipertensión

Actividades recreativas

Salud mental

Educación em salud

\footnotetext{
* Extraído da tese "Pesquisa-ação em lazer, sexualidade e educação para a saúde com pessoas que vivenciam a hipertensão arterial", Escola de Enfermagem de Ribeirão Preto da Universidade de São Paulo, 2009. ${ }^{1}$ Enfermeira. Doutora em Ciências pelo Programa de Enfermagem Psiquiátrica do Departamento de Enfermagem Psiquiátrica e Ciências Humanas da Escola de Enfermagem de Ribeirão Preto da Universidade de São Paulo. Pesquisadora do Centro Avançado de Educação para a Saúde e Orientação Sexual - Educação Preventiva em Sexualidade, DST, AIDS, Drogas e Violência, Cadastrado no Diretório de Pesquisa do CNPq. Maringá, PR, Brasil. vanessadenardi@hotmail.com ${ }^{2}$ Pedagoga. Mestre em Enfermagem. Doutora em Educação. Professora LivreDocente da Escola de Enfermagem de Ribeirão Preto da Universidade de São Paulo. Coordenadora do Grupo de Ensino, Pesquisa e Extensão do Centro Avançado de Educação para a Saúde e Orientação Sexual - Educação Preventiva em Sexualidade, DST, AIDS, Drogas e Violência, Cadastrado no Diretório de Pesquisa do CNPq. Ribeirão Preto, SP, Brasil.smvbueno@eerp.usp.br
} 


\section{INTRODUÇÃO}

A hipertensão arterial sistêmica (HAS) é uma doença crônica cuja magnitude preocupa pela sua prevalência e relação com a morbimortalidade provocada pelas doenças cardiovasculares ${ }^{(1)}$. Estima-se que a enfermidade atinja cerca de $30 \%$ da população adulta, especialmente os idosos, e afirma-se seu envolvimento com os óbitos por doença isquêmica do coração e acidente vascular encefálico $^{(1)}$.

Já foram relatados o papel da obesidade, a influência do sexo, a ingestão de sódio, o baixo consumo de potássio, o consumo exacerbado de álcool, a raça negra, o sedentarismo, a história familiar, a baixa escolaridade e o uso de medicamentos, como os contraceptivos orais, na gênese da $\operatorname{HAS}^{(1-2)}$.

Por conseguinte, questões relativas à manutenção da saúde mental em virtude dos determinantes psicossociais desta doença descritos na literatura, em especial o estres$\mathrm{se}^{(1,3)}$ que foi identificado como causa da elevação dos valores pressóricos e responsável pela gênese da $\mathrm{HAS}^{(4)}$, uma vez que provoca o aumento da reatividade cardiovascular ${ }^{(1,5)}$.

Também se destacam as próprias restrições impostas pelo tratamento como desencadeantes de percepções desagradáveis ${ }^{(6)}$ que podem gerar estresse. Por sua vez, a qualidade de vida que se perde com o estresse influencia negativamente no desejo em manter o tratamento ${ }^{(4)}$ por interferir no desejo de viver bem e melhor. Sabe-se, entretanto, que na delimitação temática HAS e estresse, muito se tem a investigar.

O lazer, contudo, vem sendo apontado como amortecedor do estresse; uma forma de diminuir os efeitos deletérios de eventos desagradáveis, especialmente por sua característica socializante ${ }^{(7)}$. É uma necessidade psicossocial cujo exercício é influenciado pela subjetividade, dependente da objetividade social e cultural. Faz-se oportuno destacar que é prazer e que, portanto, situa-se como um dos fatores fundamentais para o bem-estar ${ }^{(8)}$ e colabora para a saúde, sobretudo, para a saúde mental.

\section{O termo lazer é considerado como}

conjunto de ocupação às quais o indivíduo pode entregar-se de livre e espontânea vontade, seja para repousar, seja para divertir-se, recrear-se e entreter-se, ou ainda para desenvolver sua informação ou formação desinteressada, sua participação social voluntária ou sua livre capacidade criadora, após livrar-se ou desembaraçar-se das obrigações profissionais, familiares e sociais ${ }^{(9)}$.

Seu estudo surgiu em contraposição às demandas político-sociais do trabalho, sobretudo na sociedade ca- pitalista, num momento em que a saúde do trabalhador começou a ser reconhecida, valorizada e discutida.

Contudo, faz-se necessário compreender que o lazer possui três funções básicas: descanso, divertimento e desenvolvimento da personalidade ${ }^{(9)}$. Corroborando, afirmamos que os dias atuais têm provocado mudanças substanciais na ressignificação de valores, inclusive norteando novas experiências construtivas no lazer ${ }^{(10)}$.

Assinalamos a relação entre o lazer e a saúde mental, pois as atividades socializantes realizadas como forma de divertimento e apoio social são desencadeantes de saú$\mathrm{de}^{(7)}$. Desta forma, lazer e saúde mental são convergências que divergem do estresse, opondo-se a ele.

Esta evidência deve tornar-se importante eixo das atividades assistenciais junto aos portadores de HAS e, em destaque, nas ações educativas, pois pode colaborar com a manutenção da saúde mental por meio da prevenção e controle do estresse provocado tanto pela doença como pelo tratamento ou pelas condições de vida adversas. Neste sentido, justificamos esse trabalho por utilizarmos uma abordagem educativa para além do corpo doente, a fim de evitar o reducionismo com que normalmente são conduzidas as estratégias pedagógicas na saúde e, mais que isso, engendramos corpo, mente e contexto dos envolvidos.

Diante do exposto, este trabalho objetivou realizar, por meio de uma pesquisa-ação, a Educação para a Saúde junto a um grupo de portadores de HAS baseada na pedagogia crítico-social, partindo da percepção dos participantes quanto ao lazer, desenvolvendo atividades educativas e, posteriormente, avaliando a opinião dos envolvidos quanto ao impacto para a vida e para a saúde mental.

\section{MÉTODO}

Tratou-se de uma pesquisa-ação embasada em referencial-metodológico ${ }^{(11)}$ quanto ao seu conceito, aplicabilidade, finalidade e etapas. Encontramos, ainda, suporte metodológico aplicável na Educação para a Saúde ${ }^{(12)}$, delimitando esta pesquisa em duas fases: a primeira, quando ocorreu o levantamento dos dados sócio-demográficos e do universo temático, elencando-se os temas geradores; a segunda, constituída pela ação educativa. Estas fases são apoiadas por referencial metodológico ${ }^{(11)}$ e recebem a denominação de fase exploratória e divulgação dos resultados.

Desta forma, a investigação foi conduzida pelas técnicas: 1) grupo focal; 2) grupo-pesquisador de Freire; 3) entrevista semiestruturada. 
A população-alvo deste estudo se constituiu da totalidade de hipertensos participantes de um grupo de reunião semanal de uma unidade de saúde $(n=6)$, localizada no noroeste do Estado do Paraná-Brasil.

Os participantes somente fizeram parte da pesquisa após certificação do Comitê de Ética em Pesquisa envolvendo Seres Humanos (Parecer 1005/2009), autorização expressa da Direção deste serviço obtida pela assinatura do Termo de Permissão de Utilização dos Dados e mediante Consentimento Livre e Esclarecido dos Sujeitos, cumprindo com os preceitos regulamentados na experimentação humana, definidos pela Resolução 196/96 do Conselho Nacional de Saúde (CNS). Foram utilizados nomes fictícios, de flores, procurando preservar o sigilo e confidencialidade das participantes, de acordo com a escolha de cada uma, a saber: Rosa, Rosa Vermelha, Rosa Amarela, Margarida, Girassol e Azaléia.

Os procedimentos foram articulados ao referencial-metodológico e às técnicas de pesquisa; os sujeitos foram reunidos no segundo semestre de 2009 e os dados coletados foram separados em três momentos interligados:

O primeiro momento correspondeu aos primeiros dois encontros em que a temática lazer foi discutida por técnica de grupo-focal, gravado em MP4 Foston e transcrito e, posteriormente, submetido à técnica de análise de conteúdo, do tipo análise temática, seguindo as fases: 1) pré-análise - leitura flutuante; constituição do corpus (exaustividade, representatividade, homogeneidade, pertinência); formulação e reformulação de hipóteses (unidades de registro, de contexto, forma de categorizar); 2) exploração do material (categorias); 3) tratamento dos resultados e interpretação. No decorrer da discussão em grupo, percebemos postura repetitiva e pouco participativa. Neste momento, então, adaptamos a técnica de grupo focal com um painel dialogado, em que os participantes foram divididos em duplas, por afinidade, e distribuíram-se tarjetas em que deviam escrever coisas boas e coisas ruins e/ou problemas percebidos quanto ao lazer. Estas tarjetas foram coladas em um mural e discutidas, uma a uma. Este momento mostrou-se de grande valia porque, além de atingir o resultado, incentivou a participação, a exposição de ideias e a reflexão. No tocante à pesquisa, consolidaram-se ideias, imagens e percepções.

No segundo momento, ocorreram as entrevistas. Os dados coletados no momento anterior foram validados e explorados por entrevista individual, permitindo-nos conhecer as percepções sobre o lazer, por meio da compreensão mais acurada dos universos simbólicos. A definição das categorias, agora definitivas, se deu em confronto com as categorias anteriormente coletadas, por grupo focal, permitindo a triangulação dos dados. Estas entrevistas aconteceram no mês de outubro de 2009, em domicílio, após contato com as participantes para escolha das datas e horários, de preferência individual. Foram gravadas em apareIho MP4 da marca Foston, com média 12 min e 15 segundos, transcritas e posteriormente submetidas à técnica de análise de conteúdo ${ }^{(13)}$, do tipo Análise temática, seguindo as fases: 1) pré-análise - leitura flutuante; constituição do corpus (exaustividade, representatividade, homogeneidade; pertinência); formulação e reformulação de hipóteses (unidades de registro, de contexto, forma de categorizar); 2) exploração do material (categorias); 3) tratamento dos resultados e interpretação.

Esse momento permitiu, também, o levantamento dos temas geradores a partir das percepções dos envolvidos, constituindo o foco para a elaboração da atividade educativa e suas respectivas estratégias pedagógicas, que aconteceram no momento sequente. Os temas geradores e o referencial para a discussão e elaboração das práticas educativas foram apoiados na pedagogia da autonomia, primando por atividades educativas dialógicas e centradas nos saberes prévios do grupo, concretizando a educação como forma de emancipação e intervenção no mundo(14).

No terceiro momento, planejou-se e executou-se a ação educativa, a partir dos temas geradores elencados no momento anterior. Foram outros quatro encontros de desenvolvimento educativo, além dos outros em que juntamente à coleta também se realizaram ações desta natureza. Desta forma, a Educação para a Saúde consolidou a ação educativa, por meio de atividades discutidas nos momentos anteriores e escolhidas pelo grupo, a priori, atividades de dinâmicas de grupo para discussão sobre o lazer. Foram discutidos com o grupo e registrados os relatos quanto à opinião de cada encontro, para a avaliação formativa. Estes encontros foram gravados em aparelho MP4 da marca Foston e posteriormente transcritos, na forma de um diário, com aproximadamente $1 \mathrm{~h}$, em média. As atividades educativas aconteceram no mês de novembro de 2009. No último encontro foi discutido, pelo grupo focal, o impacto da pesquisa-ação para a vida, as possíveis mudanças de percepções e/ou e atitudes em relação ao lazer; isso nos possibilitou a avaliação somativa na perspectiva das participantes e da pesquisadora.

\section{RESULTADOS E DISCUSSÃO}

O grupo investigado possuía características de homogeneidade: todas as mulheres; com mais de 60 anos de idade (média 69,6 anos); aposentadas; viúvas ou separadas; com renda mensal de até dois salários mínimos; possuíam três a nove filhos, mas residiam sozinhas e não tinham dependentes; a maioria (5) possuía o Ensino Fundamental incompleto; eram participantes do grupo entre dois a sete anos.

Por tratar-se de pesquisa-ação, dividimos os resultados em duas fases distintas: a fase da investigação e a fase da ação.

\section{Fase 1: A fase da investigação}

Refere-se à investigação a respeito das percepções sobre o lazer, correspondendo aos momentos 1 e 2 descritos no método deste trabalho. 
O lazer foi percebido pelo grupo: 1) como estratégia de enfrentamento da solidão; 2 ) de construção tardia de independência; 3) de socialização e, em consequência; 4) de saúde mental. Estas percepções foram por nós apreendidas durante as entrevistas, pelo grupo focal e durante as próprias ações educativas - descritas a seguir por uma divisão didática, mas não metodológica, uma vez que a pesquisa-ação prevê a investigação e ação simultâneas ${ }^{(11)}$.

Verificamos que o grupo pesquisado participava do bingo como principal atividade de lazer. Assim, percebemos que o lazer é um estilo de comportamento em que qualquer atividade pode ser seu representante, desde que executado de forma livre. Dessa forma, não é clara a separação entre lazer e prazer, e ambos estão interligados. Por conseguinte, o lazer se afirma como direito, em substituição às obrigações domésticas, conjugais e familiares, em virtude dos avanços sociais que restabeleceram as normas da vida em sociedade. Não obstante, afirma-se que por mais que a sociedade clame pelo trabalho e pelas obrigações familiares, há um movimento social de concepções do lazer ${ }^{(9)}$.

De fato, especialmente a mulher idosa que vive sozinha - participante desta pesquisa - além de repensar e refazer os conceitos de papéis e obrigações, também vivencia uma ociosidade de tempo que precisa ser preenchido. Sendo assim,

para a maioria, é o lazer que constitui o conjunto de atividades mais extenso e mais significativo desta idade, mesmo quando a doença ou a miséria erguem seus obstáculos ${ }^{(9)}$

Esta realidade foi encontrada no grupo pesquisado. No grupo focal verbalizaram que:

Não vê o dia chegá, porque em casa é só solidão. Estar aqui, no bingo, é isso, uma amizade só. Uma pega o telefone da outra, aqui a gente faz amizade. Quando uma num vem a outra já sabe por que, e se num sabe já liga ou passa lá pra sabe o que aconteceu. É isso.

É muito bom. Um tipo de apoio, porque a gente se entende. A hora vai chegando, dá até coceira na sola do pé pra vim logo prá cá. É muito bom, não temos nem palavras.... Meu Deus, foi uma das melhor coisa. Não vejo a hora de chegar o dia de vir aqui. É uma terapia, uma coisa boa, sabe. Faz bem pra cabeça da gente.

Sobre a vivência com a doença e relação com o lazer, as participantes apontaram, no painel dialogado, que há interferências. Referiram que a HAS, por vezes, as impedem de atividades de lazer como a participação no baile, por elevação da pressão arterial provocada pela euforia do encontro e pela intensidade da atividade física. Também, que a frequência em festas e confraternizações teve que ser reduzi$\mathrm{da}$, pelas restrições alimentares que a doença exige - o que as isolaram ainda mais. Por fim, que as atividades de lazer, em especial o bingo, ajudam-nas a esquecer temporariamente, entre outras coisas, que são doentes.
Vale ressaltar, ainda, que referiram que as atividades de lazer foram vivenciadas de forma expressiva apenas nesta fase da vida e que as ajudaram a serem independentes, por possibilitar uma vida além dos muros de suas casas, aumentarem suas redes sociais e por conhecerem que existem prazeres na vida que ultrapassam os afazeres domésticos. Achado semelhante foi descrito na literatura ${ }^{(10,15)}$ apontando os benefícios do lazer pelo convívio social para o desenvolvimento afetivo e cognitivo de seus participantes. Além disso, o lazer possibilita novas interações e modifica o cotidiano, fazendo com que os aspectos físicos, mentais e sociais tenham resultados favoráveis para a saúde ${ }^{(15)}$.

Apoiamos a relação deste enfrentamento das condições adversas da vida e da doença na vertente sociológica da salutogênese - teoria que tenta compreender como as pessoas conseguem organizar suas vidas, apesar de situações que the são percebidas como adversas. Dessa forma, procuramos compreender a prática do lazer como movimento de escolha social.

Assim, entendemos que não há resiliência se não houver a percepção de um risco ${ }^{(16)}$. Isso posto, afirmamos que para o grupo pesquisado, a socialização permitida pelo lazer foi estratégia de resistência às situações percebidas como risco, especialmente a solidão e o risco de adoecer mentalmente ${ }^{(15,17)}$. Cumpre destacar que consideramos que o lazer somente foi assim vivido em virtude da capacidade que possuíam para buscar estratégias de enfrentamento e pelo senso de coerência que encontraram nestas atividades; a capacidade e a coerência implicam, especialmente, no suporte social encontrado e marcam a salutogênese.

Demarcamos, portanto, que houve um processo de percepção enraizada na objetividade da realidade: de que o lazer aproxima, preenche lacunas, promove bem-estar mental|(15,17). Esta realidade ao ser compartilhada, tornouse verdade aceita e vivenciada.

\section{Nas entrevistas, complementaram que:}

Eu gosto do bingo porque distrai a cabeça da gente. $E$ as hora passa. Tudo muierada, né. É bão. Jogando bingo, cada um leva sua prenda, compra e as vezes fica aquele monte, a gente perde, ganha e assim vai levando a vida (Rosa)

Distrai a cabeça. Sabe, eu penso que num pode ficá sozinha. Então, fica doida mesmo se fica sozinha, na solidão(Girassol).

O bingo é bom, não tem coisa melhor, se tivesse todo dia, todo dia eu ia(Margarida).

Ah, é bom né! Porque ta jogando, só é ruim quando eu perco, é uma coisa muito boa que vocês faz para os idosos(Rosa Vermelha).

Ah, é bom pra cabeça né(Azaléia).Bom pra distrai, se diverti. Sou bingueira!(Rosa Amarela). 
Torna-se adequado pontuar que, por serem viúvas e a maioria sem companheiro, viver esta experiência (de viuvez) foi um divisor importante nas suas atitudes, pois

a viuvez causa enorme impacto na vida das pessoas, que enfrentarão dois acontecimentos, extremamente dolorosos, simultaneamente: a separação do parceiro e o confronto com a morte e a finitude(18)

Por essa razão, defendemos que a viuvez e consequente solidão talvez tenha sido decisiva para incentivá-las ao lazer socializante, especialmente porque frente à morte do outro há a percepção da emergência de se viver intensamente ${ }^{(19)}$.

A este respeito, houve relatos:

Fiquei 54 anos casada, perdi o marido há 1 ano e 8 mês, mas to aqui levando a vida[..] (Azaléia).

As veiz a gente fica pensano que as coisa muda, né. De primeiro tinha o marido, os filho perto, agora a gente ta assim sozinha. O marido morreu, os filho tomo seus rumo... tem uma no Japão, já pensou, já faz 10 anos, tem até neta que já casou pra lá. Então a gente tinha todo mundo perto, de repente muda tudo, a gente se vê sozinha, a gente fica pensano como era a vida e como é agora, mudou bastante, né. A gente se conforma, porque a vida vai mudano, né. Mas tem que segui em frente (Rosa).

Depreendemos, portanto, que a participação nas atividades de lazer socializantes foi positiva para a ressignificação de valores, sentimentos e atitudes ${ }^{(10)}$, pois as fizeram projetar e vivenciar novas possibilidades.

\section{Fase 2: A fase da ação}

Refere-se à fase da ação educativa e sua avaliação, correspondente ao momento 3 , descrito no método desta pesquisa. Cumpre destacar que por tratar-se de ação educativa, a avaliação formativa aconteceu durante todo processo educativo e a somativa, ao final da ação educativa. No tocante à avaliação formativa, cada atividade realizada foi pontuada quanto ao envolvimento, prontidão, desenvolvimento, motivação e participação dos envolvidos, como serão apresentadas no final da exposição de cada atividade. Já a somativa delimitou-se ao final do processo educativo, pautada nas perspectivas dos envolvidos, e será apresentada no final dessa fase do trabalho.

As percepções sobre o lazer nos levaram a identificar dois temas geradores: 1) envelhecimento, lazer e doença crônica; 2) conhecimento e vivências do lazer. Partindo disso, foram elencadas as atividades educativas abaixo descritas, com alicerces pedagógicos em técnicas e dinâmicas de grupo ${ }^{(20)}$.

Para melhor ilustrar esta fase, optamos por demonstrar o caminho do planejamento pedagógico a partir dos temas geradores, estratégias pedagógicas e ações educativas junto aos hipertensos na forma de um projeto de intervenção educativa resumido (Quadro 1).
Quadro 1 - Projeto de Intervenção Educativa resumido - Hipertensos de uma Unidade de Saúde do Noroeste do Estado do Paraná, Brasil - 2009

TEMA GERADOR 1: Envelhecimento, lazer e doença crônica

ESTRATÉGIAS PEDAGÓGICAS: Espaços de discussão sobre envelhecimento, lazer e doença crônica: promovendo a conscientização

\section{AÇÕES EDUCATIVAS:}

1) Atividade 1: grupo focal como espaço de discussão, troca de saberes e aproximação ao tema lazer.

- Objetivos educacionais: discutir a temática lazer; experimentar o diálogo; vivenciar o respeito às ideias, aos conceitos, aos valores e aos sentidos atribuídos.

- Método, Materiais e Procedimentos: grupo focal, gravador e questões norteadoras.

2) Atividade 2: painel dialogado sobre envelhecimento, doença crônica e lazer.

- Objetivos educacionais: relacionar as temáticas envelhecimento, doença crônica e lazer.

- Método, Materiais e Procedimentos: adaptação da técnica painel dialogado, cartolinas, canetinhas, tarjetas de papel, fita adesiva, gravador.

3) Atividade 3: dinâmica do concordo, não concordo e ainda não sei

- Objetivos educacionais: compartilhar valores, atitudes e comportamentos sobre o enfrentamento das condições adversas da vida, da hipertensão arterial e a prática e dificuldades no lazer.

- Método, Materiais e Procedimentos: dinâmica de grupo, papéis com as frases: concordo, não concordo, ainda não sei.

TEMA GERADOR 2: Conhecimento e vivências do lazer

ESTRATÉGIAS PEDAGÓGICAS: Oficinas de atividades recreativas e socializantes

\section{AÇÕES EDUCATIVAS:}

4) Oficina: $O$ bingo

- Objetivos educacionais: experimentar momentos de lazer e socialização.

- Método, Materiais e Procedimentos: jogo socializante (bingo), cartelas de bingo, prêmios, gravador.

Destacamos, entretanto, que os achados nestas atividades já foram descritas na fase 1: investigação, reforçando que na pesquisa-ação não há dissociação entre fazer e pesquisar, e que ambos podem ocorrer simultaneamente, como neste trabalho.

A Atividade Educativa 1: grupo focal como espaço de discussão, troca de saberes e aproximação ao tema lazer. Além dos objetivos educacionais apresentados, serviu como técnica de pesquisa, pois permitiu discutir sobre esta temática, oportunizando um canal de diálogo entre o grupo e favorecendo o respeito às ideias, aos conceitos, aos valores e aos sentidos atribuídos. As participantes foram organizadas em círculo, e a discussão foi conduzida como um debate. $O$ mediador conduziu as perguntas: o que é lazer para vocês? O que isto representa na vida de vocês? O que vocês gostam de fazer? A participação, de início, precisou ser ativamente acionada pelo mediador. 
No entanto, todas falaram, expuseram suas experiências pessoais e suas percepções, especialmente ao sentirem-se acolhidas pelo próprio grupo. Avaliamos que a discussão fluiu a contento. Percebemos que ao final do primeiro encontro, uma das participantes, surpreendentemente a mais inibida, verbalizou: nóis qué que vocês fica aqui com nóis. É bão, né. Vocês traiz coisa boa (...). Ao perguntar se o encontro foi bom, responderam que foi bom, fez a gente pensá. Como avaliação formativa, portanto, consideramos que a atividade possibilitou a reflexão(21) a troca de experiências, o prazer pelo convívio coletivo ${ }^{(10,19)}$.

A Atividade Educativa 2: painel dialogado sobre envelhecimento, doença crônica e lazer, além de atingir o objetivo educacional proposto também aprofundou a discussão destas temáticas, consolidando a investigação. O grupo foi dividido em duplas e recebeu tarjetas para construção do painel: melhores e piores coisas do lazer. Feito isso, cada dupla fixou seu painel na parede e discutimos, durante aproximadamente 30 min., quanto às concordâncias/discordâncias, opiniões e vivências. A discussão foi gravada e depois transcrita. A avaliação feita pela observação atenta de todo processo foi de grande valia para permitir na nossa apreensão de que: a capacidade cognitiva era comprometida; havia resistência para atividades escritas porque possuíam dificuldade de exposição verificada por meio de verbalizações: tenho vergonha de escrever porque nossa letra é feia demais ou ainda num sei escrever direito, não, escreve pra nóis que você tem a letra mais bonita. Incentivamos a atividade autônoma, mas respeitamos as que se negavam a escrever e escrevemos por elas. No entanto, ao finalizar a atividade vimos algumas que discretamente começaram a escrever em papéis sobre a mesa, como que buscassem superação e experimentassem suas capacidades. Quanto à avaliação formativa depreendemos que este momento foi de grande valor para consolidar a discussão temática, servindo ainda como norteador para o remodelamento da nossa linguagem, para nos fazer entender pelo grupo. Isto colaborou, sobremaneira, para o planejamento das entrevistas individuais que aconteceriam, conforme exposto nos métodos desse trabalho, pertencentes ao segundo momento da pesquisa. Possibilitou-nos, também, evidenciar um clima mais aberto entre o grupo. Quando questionamos o que gostariam que abordássemos nos encontros sequentes, referiram que podemos falar de qualquer coisa, porque só estamos entre mulheres mesmo, não tem problema falar besteira, se for o caso. Neste momento tivemos a concretização de que a dialogicidade estava colocada, de forma marcante ${ }^{(13)}$. Ao perguntar sobre o que acharam deste encontro, verbalizaram que as fez pensar ${ }^{(21-22)}$, além de treinar a escrita; uma delas sutilmente elogiou o grupo pela qualidade dos painéis.

A Atividade Educativa 3: dinâmica do concordo, não concordo e ainda não sei. Permitiu que percebêssemos valores, atitudes e comportamentos sobre o enfrentamento das condições adversas da vida, da hipertensão ar- terial e a prática e dificuldades no lazer, além do objetivo educacional estabelecido. Foram utilizados papéis com as frases: concordo, não concordo, ainda não sei. Foram delimitados três espaços, separados imaginariamente, por uma linha. Em cada espaço havia um recado na parede: concordo, não concordo, ainda não sei. Foram lidas algumas frases e os participantes se posicionaram em cada espaço, de acordo com sua opinião. A cada manifestação da opinião, discutir a razão das opiniões. As frases foram: 1 A terceira idade é a melhor fase da vida; 2 - A pressão alta não atrapalha em nada na minha vida; 3 - Não gosto de bingo; 4 - Não gosto de vir aos encontros de quinta-feira; 5 - Gosto muito de conhecer outras pessoas; 6- Não gosto de dançar e passear; 7 - Por causa da minha doença não posso comer muitas coisas que tenho vontade; 8- Gosto muito de assistir televisão; 9 - Conheço muitas pessoas que têm a mesma doença que a minha e elas me ajudam muito para enfrentá-la; 10 - Não tenho medo de ficar doente; 11 - Não gosto de ir à igreja; 12 - Adorei ter me aposentado; 13 - Adoro fazer compras; 14 - Durante o dia, passo muitas horas sem ter o que fazer; 15 - Queria ter mais momentos de lazer durante a semana.

Como avaliação formativa, percebemos que esta dinâmica serviu para estimular a reflexão, a comunicação, a exposição de ideias, o respeito pelas opiniões alheias ${ }^{(21)}$ e de descontração. A participação foi grande e intensiva. Algumas das frases acima foram improvisadas pelas participantes, tamanha a vontade de participar da atividade de forma descontraída e animada.

A Atividade Educativa 4: o bingo, aconteceu em todos os encontros, pois já era executado pelo grupo há vários anos e foi a atividade escolhida para ser realizada durante esta pesquisa-ação. $\mathrm{O}$ grupo era composto por mais algumas pessoas, além das participantes desta pesquisa, mas não as segregamos. Procuramos executar as atividades de forma aberta para todos que quisessem participar. As próprias participantes levavam as cartelas para o bingo e os prêmios, que denominavam de prendas. Nossa participação foi no sentido de ajudá-las, apoiá-las e conduzir o jogo sem, contudo, interferir nas normas que elas já possuíam para sua realização. A avaliação formativa dessa atividade concretizou nossa percepção sobre a organização social das participantes, sobre a alegria dos encontros, sobre a vontade de estarem juntas e, especialmente, a prática de uma atividade recreativa que ressignificou suas vidas e preveniu o surgimento de sentimentos hostis ${ }^{(17)}$ impactando na saúde mental.

Destacamos que as avaliações formativas nas atividades supracitadas foram de grande valia para as ações educativas, pois o processo avaliativo cumpriu relevante papel na compreensão contextualizada do que e como se ensinava e se aprendia; proporcionou-nos segurança e possibilidade constante de planejamento, com vistas à adequação do conteúdo programático.

$\mathrm{Na}$ avaliação somativa, entretanto, pautamo-nos na percepção individualizada dos participantes e da pes- 
quisadora. Desta forma, na perspectiva dos participantes, as participantes relataram que o convívio foi muito bom e nas primeiras perguntas queriam se esconder do gravador, e que foi muito difícil se abrir, mas a naturalidade e confiança sentida permitiram maior participação. Sobre as mudanças, o lazer passou a ser entendido como direito e necessidade, porque nunca haviam pensado sobre isto. Disseram sentirem-se mais seguras ao verificar que muitas experimentam as mesmas vivências e possuem a mesma percepção; ou, ainda, que existem outras realidades e percepções que podem ser compartilhadas, sinalizando a possibilidade de abertura ao diálogo e ao desenvolvimento cognitivo-afetivo ${ }^{(20-22)}$.

Também relataram que passaram a se conhecer mais e que os encontros ficaram mais alegres pelas atividades inovadoras que foram realizadas. Também afirmaram, como já relatado, a tamanha motivação para os encontros sinalizados como favorável para a saúde da cabeça, para distrair, esquecer do estresse, conversar, conviver com outras pessoas, demarcando o impacto para a saúde mental e para a qualidade de vida ${ }^{(7,17)}$.

$\mathrm{Na}$ perspectiva da pesquisadora, considerou-se que o processo investigativo e educativo possibilitado pela pesquisa-ação foi, sem dúvida, marcado por desafios, relativos: 1) à aceitação do grupo pela pesquisadora e da pesquisadora pelo grupo, pois foram universos distintos que precisavam ser colocados em diálogo; 2) à complexidade do tema gerador e o preparo das ações educativas, permeadas pela dialogicidade, que determinou maior flexibilidade e, em contrapartida, menor controle prévio das ações; 3 ) de ordem avaliativa, pois enquanto processo, não era costumeiramente praticado.

Avaliar é sempre algo cercado de incertezas, quando possui finalidade classificatória. Não sendo este o fim da avaliação em questão, possibilitou uma nova experiência, enriquecedora em detalhes. Nossa experiência confirmou a argumentação de que a dialogicidade, aplicada nas estratégias de educação e saúde, é forma de valorizar o saber popular, instrumentalizando os participantes para a transformação de sua realidade e de si mesmo, tornando-os corresponsáveis ao mesmo tempo em que incrementa sua capacidade criadora e possibilita uma ação educativa pautada no cuidado às pessoas ${ }^{(22)}$. Além disso, consideramos que a estratégia educativa, quando apoiada pela emancipação dos envolvidos, permite a tão necessária integralidade da assistência em saúde - prevista como princípio do Sistema Único de Saúde ${ }^{(21)}$, por valorizar questões de vida e saúde que extrapolem o corpo doente.
Desta forma, entendemos que o valor maior dessa pesquisa não se manifestou na mudança radical e informada de comportamentos. Até mesmo porque a educação não é pontual e imediata. O maior valor se manifestou na prática educativa que oportunizou momentos pedagógicos com estímulos à autonomia, respeito aos saberes e integralidade da assistência; também se consolidou nas pequenas alterações de atitudes: o desejo de estar juntas, de conversar, de permanecer juntas, de trocar ideias e acolherem-se, no sentido mais terno desta palavra. Sem dúvida, o momento oportunizado pelos encontros contribuiu para a promoção da saúde mental.

\section{CONCLUSÃO}

Depreendemos que o lazer foi sentido e vivido por essas mulheres como forma de enfrentar a solidão, permitindo a socialização, o contentamento pela vida e, consequentemente, promovendo a saúde mental. Foi visto, também, como forma de enfrentamento e tratamento da hipertensão arterial sistêmica (HAS). Os temas geradores elencados permitiram a programação de ações educativas em que a dialogicidade foi colocada em prática, utilizando de estratégias educativas como dinâmicas e grupos de discussão, favorecendo condições que permitiram a socialização e as trocas de experiência. A valorização dos conhecimentos prévios existentes pelo grupo, o planejamento educativo compartilhado e cuidadosamente definido, os vínculos estabelecidos e o consequente reforço das capacidades humanas para a criatividade e resolução de problemas foram resultados imensuráveis, mas observáveis na prática educativa e coerentes com a pedagogia freireana.

A limitação do estudo está no número de participantes, que não permitiu generalizações quanto às percepções do lazer para a população-alvo. No entanto, oportunizou a programação de ações educativas de forma individualizada e contextualizada, focadas para a demanda existente, independente do número de participantes.

Desejamos, arduamente, que muitos outros trabalhos possam questionar o que existe colocado como verdade absoluta nas ações educativas opressoras voltadas à saúde, e que separam a saúde mental da saúde orgânica. Desta forma, partindo de uma população caracterizada como portadores de uma doença crônica clínica, pudemos compreender o impacto de ações educativas que ultrapassam o corpo doente, e vislumbram a integralidade humana, incluindo a saúde mental. 
1. Sociedade Brasileira de Hipertensão Arterial; Sociedade Brasileira de Cardiologia; Sociedade Brasileira de Nefrologia. VI Diretrizes Brasileiras de Hipertensão Arterial. Arq Bras Cardiol. 2010;95(1 Supl 1):1-51.

2. Irigoyen MC, Lacchini S, De Angelis K, Cichelini LC. Fisiopatologia da hipertensão: o que avançamos? Rev Soc Cardiol Estado São Paulo. 2003;13(1):20-45.

3. Sparrenberger F, Moreira LB, Canepele MCGL. Associação entre estresse e hipertensão. Hipertensão. 2004;7(3):96-99.

4. Lipp MEN. Controle do estresse e hipertensão arterial sistêmica. Rev Bras Hipertens. 2007; 14(2):89-93.

5. Guyton AC, Hall JE. Tratado de fisiologia médica. São Paulo: Elsevier; 2006.

6. Bonomo E, Caiaffa WT, César CC, Lopes ACS, Lima-Costa MF. Consumo alimentar da população adulta segundo perfil sócio-econômico e demográfico: Projeto Bambuí. Cad Saúde Pública. 2003;19(5):1461-71.

7. Ponde MP, Caroso C. Lazer como fator de proteção da saúde mental. Rev Ciênc Med. (Campinas). 2003;12(2):163-72.

8. Jannuzzi FF, Cintra FA. Atividades de lazer em idosos durante a hospitalização. Rev Esc Enferm USP. 2006;40(2):179-87.

9. Dumazedier J. A revolução cultural do tempo livre. São Paulo: Studio Nobel/SESC; 1999.

10. Gáspari JC, Schwartz GM. O idoso e a ressignificação emocional do lazer. Psicol Teoria Pesq. 2005;21(1):69-76.

11. Thiollent M. Metodologia da pesquisa-ação. São Paulo: Cortez; 2007.

12. Bueno SMV. Marco conceitual e referencial teórico da educação para a saúde: orientação à prevenção de DST/AIDS e drogas no Brasil para crianças, adolescentes e adultos jovens. Brasília; 1997/8.
13. Bardin L. Análise de conteúdo. Lisboa: Edições 70; 2002.

14. Freire P. Pedagogia da autonomia: saberes necessários à prática educativa. São Paulo: Paz e Terra; 1996.

15. Sousa MNA, Bezerra ALD, Alexandre JNM, Almeida JLS, Motta VLB. Lazer e qualidade de vida na terceira idade: percepção dos idosos de um Centro de Convivência Campinense. Qualit@s Rev Eletr [Internet]. 2010 [citado 2011 maio 25];9(1):1-14. Disponível em: http://revista.uepb.edu.br/ index.php/qualitas/article/viewFile/318/407

16. Paludo SS, Koller SH. Resiliência na rua: um estudo de caso. Psicol Teoria Pesq. 2005; 21(2):187-95.

17. Davim RMB, Dantas SMM, Lima VM, Lima JFV. O lazer diário como fator de qualidade de vida: o que pensa um grupo da terceira idade. Ciênc Cuidado Saúde. 2003;2(1):19-24.

18. Baldin CB, Fortes VLF. Viuvez feminina: a fala de um grupo de idosas. Rev Bras Ciênc Env Human. 2008;5(1):43-54.

19. Neri ALI. O legado de Paul B. Baltes à psicologia do desenvolvimento e do envelhecimento. Temas Psicol. 2006;14 (1):17-34.

20. Antunes $C$. Manual de técnicas de dinâmicas de grupo de sensibilização de ludopedagogia. Petrópolis: Vozes; 2002.

21. Machado MFAS, Monteiro EMLM, Queiroz DT, Vieira NFC, Barroso MGT. Integralidade, formação de saúde, educação em saúde e as propostas do SUS: uma revisão conceitual. Ciênc Saúde Coletiva. 2007;12(2):335-42.

22. Pires CGS, Mussi FC. Reflecting about assumptions for care in the healthcare education for hypertensive people. Rev Esc Enferm USP [Internet]. 2009 [cited 2011 May 25];43(1):22936. Available from: http://www.scielo.br/pdf/reeusp/ v43n1/en_30.pdf 